\title{
Primary Hepatic Carcinoid Tumor
}

\section{A Case Report}

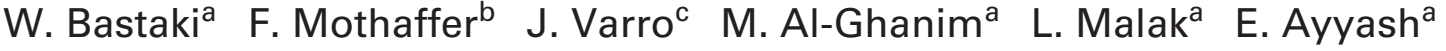 \\ S. Asfar ${ }^{a, d}$ \\ ${ }^{a}$ Liver Surgery Unit and ${ }^{b}$ Department of Pathology, Mubarak Al-Kabeer Hospital, ${ }^{c}$ Department of Radiology, \\ Ameri Hospital, and ${ }^{\mathrm{d}}$ Department of Surgery, Faculty of Medicine, Kuwait University, Kuwait
}

\author{
Key Words \\ Primary carcinoid • Liver carcinoid • Liver tumor • \\ Carcinoid tumors
}

\begin{abstract}
Objectives: To describe a rare case of primary carcinoid tumor of the liver and its management. Clinical Presentation and Interventions: A 44-year-old Nigerian male presented with a big inoperable liver mass, which proved to be a carcinoid tumor by fine needle aspiration cytology. Extensive search for a primary lesion including laparotomy and peroperative ultrasound failed to find a primary lesion in the gastrointestinal tract and pancreas. Percutaneous embolization of the tumor followed by complete dearterializations of the liver seemed to have halted the growth of the tumor. The patient remained well with normal liver function tests for 56 months when he decided to go back to his country. Conclusion: The result showed that dearterializations of a primary inoperable carcinoid of the liver offered good palliation.
\end{abstract}

Copyright (C) 2005 S. Karger AG, Basel

\section{Introduction}

Carcinoid tumors are well-differentiated endocrine neoplasms. They originate from special enterochromaffin cells and are commonly seen in the gastrointestinal tract. The first case of carcinoid tumor was reported by Obern- dorfer in 1907 [1]. Primary carcinoid tumors of the liver are extremely rare; the first case was reported by Primack in 1971 . Since then, only 45 cases have been reported in the English literature [1-7].

Considering the slow progression of the tumor, longterm follow-up is required to exclude occult extrahepatic primaries. We report a 44-year-old male with extensive inoperable primary hepatic carcinoid.

\section{Case Report}

A 44-year-old Nigerian was admitted to hospital because of vague upper abdominal and right hypochondrial pain of 1-year duration. The pain was dull in nature and not associated with any systemic symptoms such as jaundice, vomiting, flushing or diarrhea. There was no history of weight loss. Physical examination showed a muscular healthy-looking man. Abdominal examination revealed a large, firm, lobulated and tender mass in the right hypochondrium. It extended $4 \mathrm{~cm}$ below the costal margin and was moving with respiration. Clinically, the mass seemed to be related to the liver. There were no ascites. Liver function test showed an alkaline phosphatase of 587 IU/1 (26-88 IU/1), AST 70 IU/1 (10$42 \mathrm{IU} / 1)$ and ALT $84 \mathrm{IU} / 1$ (10-60 IU/1). Serum hepatitis B surface antigen and hepatitis $\mathrm{C}$ antibody were negative.

Ultrasound examination of the abdomen showed a large mass occupying most of the right lobe of the liver with a central hypoechoic region. Smaller lesions were also found occupying both lobes. The spleen was slightly enlarged. Chest X-ray was normal. CT scan confirmed the ultrasound findings (fig. 1). The para-aortic lymph nodes were not enlarged, the pancreas was normal and there was no fluid in the peritoneal cavity.

Fine needle aspiration cytology from the big mass in the right lobe of the liver showed a cellular lesion composed of small uniform

\section{KARGER}

Fax +41613061234 E-Mail karger@karger.ch www.karger.com
(C) 2005 S. Karger AG, Basel

$1011-7571 / 05 / 0144-0288 \$ 22.00 / 0$

Accessible online at:

www.karger.com/mpp
Sami Asfar, MB, CH.B, MD (UK), FRCSEd, FACS, Prof of Surgery

Department of Surgery, Faculty of Medicine, Kuwait University PO Box 24923

13110 Safat (Kuwait)

Tel. +965 531 9475, Fax +965 531 9597, E-Mail sami@hsc.edu.kw 
Fig. 1. CT scan of the liver. The left image shows a large mass occupying the right lobe. Smaller lesions are seen in the left lobe of the liver. Right image: the tumor is highly vascular showing extensive peripheral enhancement with big central necrosis (arrows).

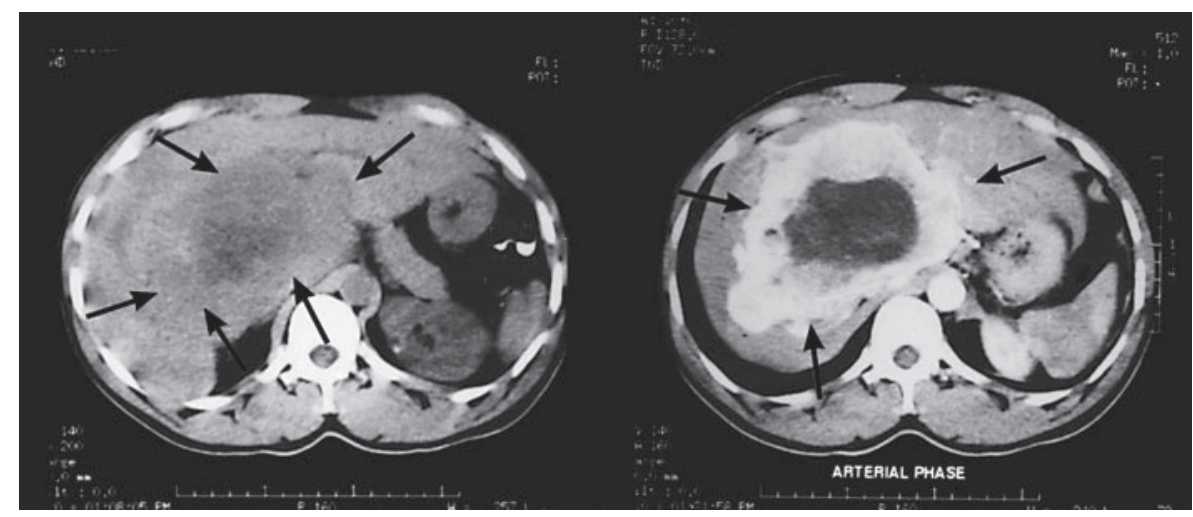

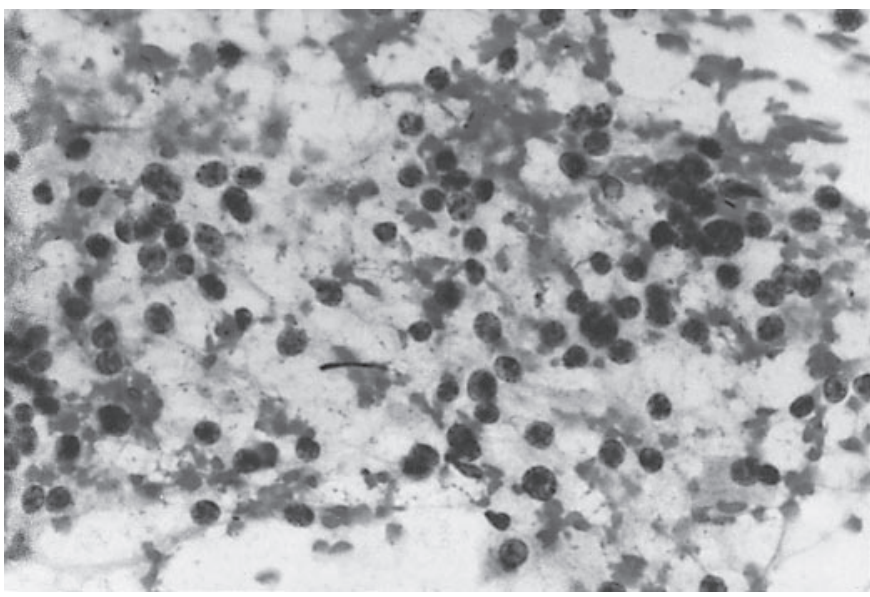

Fig. 2. Fine needle aspiration cytology from the big mass in the right lobe of the liver shows a cellular lesion composed of small uniform cells lying scantly or forming loosely arranged clusters. The cytoplasm is scanty showing fine eosinophilic granules in some. The nuclei are uniform, small with granular chromatin. Papanicolaou. $\times 400$.

cells lying scantly or forming loosely arranged clusters. The cytoplasm of these cells was scanty with fine eosinophilic granules in some. The nuclei were uniform, small and rounded to oval with granular chromatin (fig. 2). The findings were suggestive of carcinoid tumor of the liver. Accordingly, we started an intensive search for the primary tumor. Twenty-four-hour urine 5-HIAA was $25 \mathrm{mg}$ /day (normal, $<20 \mathrm{mg} /$ day). Serum levels of gastrin, calcitonin, adrenaline, noradrenaline, dopamine and ACTH were normal. $\alpha$-Fetoprotein and carcinoembryonic antigen were normal. ${ }^{111} \mathrm{In}$ octreotide scan and ${ }^{99 \mathrm{~m}} \mathrm{Tc}$ colloid scan showed intense uptake in the right lobe of the liver, indicating the presence of a somatostatin receptor-positive neuroendocrine tumor. Upper and lower gastrointestinal endoscopy, barium follow-through and a lung CT scan showed no abnormality.

The tumor was inoperable because of its size and involvement of both lobes. Therefore, it was decided to try arterial embolization

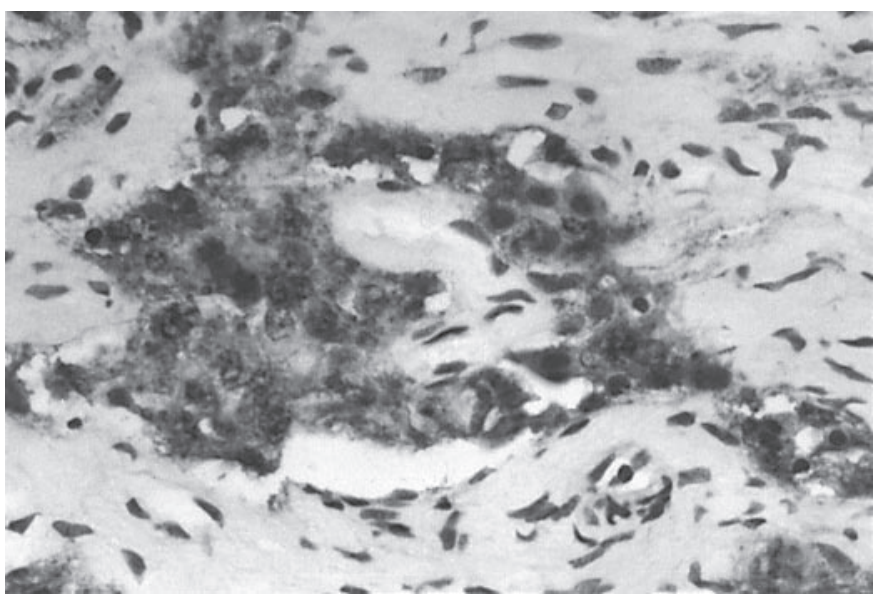

Fig. 3. Positive immunohistochemical stains for chromogranin A, consistent with a neuroendocrine tumor (carcinoid). Chromogranin A. $\times 400$.

to possibly downsize the lesion and as a palliative procedure. A selective celiac artery angiogram demonstrated a highly vascular large mass in the right lobe of the liver and smaller lesions in the left lobe. Devascularization of the tumor by embolization of the liver lesion was done with PVA particles $(500 \mu \mathrm{m})$. The feeding branches from the common hepatic artery were occluded with spring coils to achieve near-total devascularization of the tumor. Following this procedure, the patient showed all the clinical signs and symptoms of tumor necrosis (fever, abdominal pain and tenderness with abnormal liver function tests). He was given i.v. antibiotics, steroids, anti-inflammatory medications and i.v. fluids. After 5 days, he slowly recovered and the liver enzymes reverted to baseline levels.

After a few weeks of his full recovery an exploratory laparotomy was performed searching for the primary tumor. The small intestine, large bowel and the appendix were normal and there was no 
lymphadenopathy. The liver findings were confirmed and an intraoperative ultrasound of the pancreas did not detect any abnormality. A biopsy from the right lobe mass was taken and an appendectomy was performed. It was decided to completely dearterialize the tumor. An aberrant left hepatic artery and a big accessory right hepatic artery were found arising from the left gastric and gastroduodenal arteries, respectively; both were ligated and cut. The common hepatic artery was already occluded by the preoperative embolization.

Histological examination of the liver biopsy showed nests of monotonous small cells within an area of dense sclerosis and focal calcification. The tumor cells had round to oval nuclei with one or more small basophilic nucleoli and relatively abundant amphophilic to eosinophilic cytoplasm. Small brightly eosinophilic granules were visible within several cells. Immunohistochemical stains for chromogranin A were positive (fig. 3). These features are consistent with a neuroendocrine (carcinoid) tumor because of the absence of mitotic activity. Sections of the appendix showed no evidence of carcinoid tumor.

Postoperatively the patient developed fever, leukocytosis and raised liver enzymes due to tumor necrosis. The symptoms improved within a week and liver enzymes returned to the preoperative levels. He was finally discharged in a good general condition.

The patient remained under regular follow-up for 56 months. During his last visit before going back to his country, he looked healthy, had gained weight, and his liver enzymes and serum bilirubin were within the normal ranges.

\section{Discussion}

Carcinoid tumors are well-differentiated endocrine neoplasms, and they are commonly seen in the gastrointestinal tract. They originate from special enterochromaffin cells in the neural crest called Kulchitsky cells. These cells are present in several organs in the body. The first case of carcinoid tumor was reported by Oberndorfer in 1907 [1]. Recently, these tumors were defined as neuroendocrine tumors [2] and classified into neuroendocrine carcinoma and carcinoid.

Neuroendocrine carcinomas are malignant epithelial neoplasms with high mitotic activity, necrosis and vascular invasion. Carcinoids, the low-grade malignant counterpart, are generally well differentiated with minimal pleomorphism [2]. In a review of 2,837 carcinoid tumors, Godwin [3] reported that most carcinoid tumors originated from the appendix, rectum and ileum.

Primary hepatic carcinoids are very rare; Primack reported the first case in 1971 [4]. It is assumed that primary hepatic carcinoid arises from endocrine cells in the intrahepatic biliary tree [5]. Specific markers for hormone production have shown a variety of secretory products in primary carcinoids, including gastrin, pancreatic polypeptide, vasointestinal polypeptide, calcitonin, parathor- mone, ACTH, serotonin, insulin and somatostatin [1]. In the case reported here, there were no endocrine symptoms and 5-HIAA was normal.

Immunohistochemical staining of resected specimens is usually positive when stained with antibodies such as antineuroendocrine, antineuron-specific enolase and antichromogranin A [1]. Electron microscopic studies confirm the neurosecretory nature of these tumors by demonstrating cytoplasmic dense core granules. Of the 45 cases of primary liver carcinoid reported so far in the literature only 2 cases had features of carcinoid syndrome, 1 of which was followed for 18 years [4].

Carcinoids of the liver are usually metastatic from a primary tumor in the gastrointestinal tract. Accordingly, extensive preoperative investigation and even surgical exploration are warranted to find the primary tumor. In addition, a close and prolonged postoperative follow-up is necessary to unravel any dormant primary lesion, which may show later. In the present case no evidence was found either preoperatively or at surgery, or during the 56-month follow-up.

Complete resection of primary liver carcinoid is expected to give the most favorable outcome $[1-4,6,7,9$, 10]. Among the 18 cases reported up to 1999 and cited by Sano et al. [7] and which underwent total excision, 13 lived for periods ranging from 7 to 12 years; only 2 unresectable cases underwent arterial embolization as an initial treatment and both died within 3 months after the first embolization. The presence of extrahepatic metastases in these patients may explain the poor outcome. Nonetheless, arterial embolization might be an effective option when an unresectable tumor is confined to the liver [8, $10]$, as in this case.

The overall 5-year survival for patients with primary hepatic carcinoid is reported to be $25-50 \%$ [2, 7]. This is a more favorable prognosis than that for patients presenting with metastatic liver carcinoids $[1,2,7,9,10]$.

\section{Conclusion}

This report shows that dearterializations of a primary inoperable carcinoid of the liver offers good palliation. 


\section{References}

-1 Mizuno Y, Ohkohchi N, Fujimori K, Doi H, Orii T, Asakura T, Kimura N, Pilichowska M, Inomata M, Satomi S: Primary hepatic carcinoid tumor: A case report. Hepatogastroenterology 2000;47:528-530.

- 2 Andreola S, Lombardi L, Auisio RA, Mazzaferro V, Koukouras D, Doci R, Gennari L, Makowka L, Starzl TE, Van Thiel D: A clinicopathological study of primary hepatic carcinoid tumors. Cancer 1990;65:1211-1218.

-3 Godwin JD: Carcinoid tumors: An analysis of 2837 cases. Cancer 1975;36:560-569.

4 Mehta DC, Warner RRP, Parnes I, Weiss M: An 18-year follow-up of primary hepatic carcinoid with carcinoid syndrome. J Clin Gastroenterol 1996;23:60-62.
5 Takayasu K, Muramatsu Y, Sakamoto M, Mizuguchi Y, Moriyama N, Wakao F, Kousuge T, Takayama T, Hirohashi S: Findings in primary hepatic carcinoid tumor: US, CT, MRI, and angiography. J Comput Assist Tomogr 1992;16:99-102.

6 Krishnamurthy SC, Dutta V, Pai SA, Kane SV, Jagannath P, Desouza LJ, Deshpande R, Desai PB: Primary carcinoid tumour of the liver: Report of four resected cases including one with gastrin production. J Surg Oncol 1996;62:218 221.

7 Sano K, Kosuge T, Yamamoto J, Shimada K, Takayama T, Yamasaki S, Makucchi M: Primary hepatic carcinoid tumors confirmed with long-term follow-up after resection. Hepatogastroenterology 1999;46:2547-2550.
-8 Stehlin JS, De Ipolyi PD, Greeff PJ, Mc Gaff CJ, Davis BR, McNary L: Treatment of cancer of the liver: Twenty years experience with infusion and resection in 414 patients. Ann Surg 1988;208;23-35.

-9 Nave H, Mossinger E, Feist H, Lang H, Raab $\mathrm{H}$ : Surgery as a primary treatment in patients with liver metastases from carcinoid tumors: A retrospective, unicentric study over 13 years. Surgery 2001;129:170-175.

10 Marshall JB, Bodnarchuk G: Carcinoid tumors of the gut: Our experience over three decades and review of the literature. J Clin Gastroenterol 1993;16:123-129. 